\title{
Barriers to Organized Mammography Screening Programs in Hungary: A Questionnaire-based Study of 3,313 Women
}

\author{
MIHÁLY ÚJHELYI ${ }^{1}$, DÁVID PUKANCSIK ${ }^{1}$, PÉTER KELEMEN ${ }^{1}$, ESZTER KOVÁCS ${ }^{2}$, ISTVÁN KENESSEY ${ }^{3,4}$, \\ MIHÁLY BAK ${ }^{5}$, MIKLÓS KÁSLER ${ }^{6}$, TIBOR KOVÁCS ${ }^{7}$ and ZOLTÁN MÁTRAI ${ }^{1}$ \\ Departments of ${ }^{1}$ Breast and Sarcoma Surgery, ${ }^{2}$ Radiological Diagnostics, \\ ${ }^{5}$ Cytopathology and ${ }^{3}$ National Cancer Registry, National Institute of Oncology, Budapest, Hungary; \\ ${ }^{6}$ National Institute of Oncology, Budapest, Hungary; \\ ${ }^{4}$ Second Department of Pathology, Semmelweis University, Budapest, Hungary; \\ ${ }^{7}$ Breast Unit, Guy's Hospital, London, U.K.
}

\begin{abstract}
Background/Aim: Despite well-organized Hungarian invitational mammography screening, participation rates have never reached 50\%. This is similar to rates in Central Eastern Europe. In order to reduce breast cancer mortality, the participation rate should be at least 70\%. This questionnaire-based study assessed the barriers associated with low adherence rates. Materials and Methods: Women 4565 years of age were interviewed by questionnaire containing 15 structured questions focused on socioeconomic status and barriers to screening. Results: A total of 3,313 women completed the questionnaire. The main reasons for avoiding screening were work absenteeism (18.9\%), fear of painful examination (18.39\%), and poor understanding of mammography screening (14.94\%). Conclusion: Education is required to increase awareness among women about the utility and availability of breast screening services. This report provides information on the appropriate level of intervention needed to increase screening participation in Hungary and other developing countries in Central Eastern Europe to reduce breast cancer-related mortality.
\end{abstract}

Breast cancer is one of the most prevalent malignancies and is the main cause of cancer death for women in the Western world (1). Most breast cancer deaths are caused by locally advanced or stage IV disease. Therefore, many countries have implemented organized mammography screening programs (OMSP) in order to detect breast cancer at an earlier stage and reduce breast cancer mortality (1-3). In

Correspondence to: Mihály Újhelyi, Ráth György str. 7-9, 1122 Budapest, Hungary. Tel: +36 12248600, Mobile: +36 308380140, e-mail: ujmisi@gmail.com

Key Words: Breast neoplasms, mammography, mass screening, surveys and questionnaires.
January 2002, Hungary initiated a nationwide OMSP for women 45-65 years of age with a biannual screening interval (4). The efficacy of mammography screening in preventing breast cancer deaths has been shown in randomized controlled trials, with a reduction of mortality between $17 \%$ and $32 \%$ (5-9). However, some recent studies have questioned the efficacy of early-stage tumour detection in reducing mortality $(10,11)$. These authors believe that in advanced breast cancer effective adjuvant therapy may play a greater role in reducing breast cancer mortality than screening (12-14).

One of the most important roles of OMSP is to disclose breast tumours before they become palpable, during stage 0 , thereby decreasing the percentage of advanced breast cancer cases and thus reducing breast cancer-related mortality (1517).

The Hungarian National Cancer Registry recorded nearly 7,900 new cases of breast cancer in women, with more than 2,100 deaths in 2014. While not statistically significant, the incidence of breast cancer in Hungary has been increasing since the implementation of an OMSP, but the mortality has not changed measurably between 2002 and $2014(18,19)$ (Figure 1). According to the World Health Organization (WHO), the breast screening adherence rate should be at least $70 \%$ in order to reduce breast cancer mortality (20). Despite the fact that screening is invitational and free of charge, participation in the Hungarian OMSP has never reached $70 \%$. The total screening and diagnostic coverage of mammography examinations was $53.46 \%$ from 2002 to 2003, 50.8\% from 2004 to 2005, 49.7\% from 2006 to 2007 and $50.1 \%$ from 2008 to 2009 . Thus, participation in the Hungarian OMSP program did not change considerably between 2002 and 2009 (21-23).

The association between marital status, education level, socioeconomic characteristics, knowledge, and beliefs about breast cancer and mammography screening have not been 


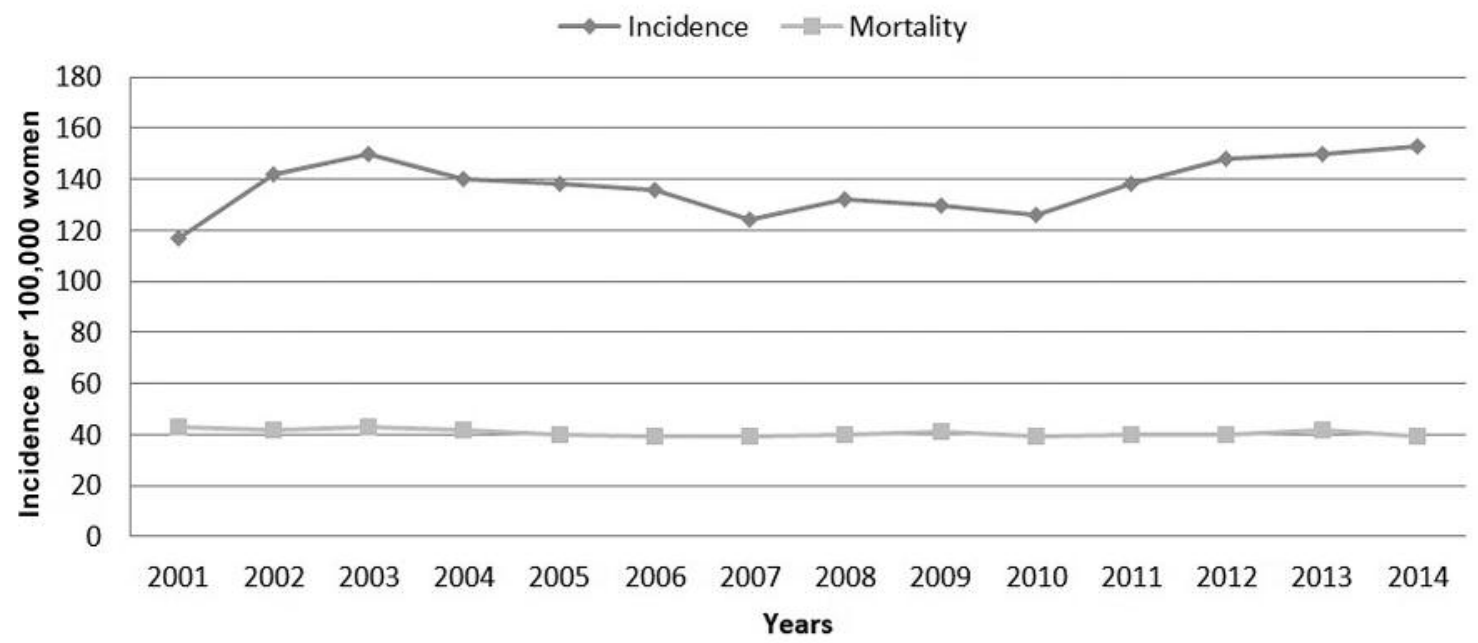

Figure 1. Breast cancer incidence and mortality per 100,000 women in Hungary between 2001 and 2014 (19).

Table I. Breast cancer screening programs in 2010 and last update: coverage by test, coverage by invitation, participation rate in Austria, Bulgaria, Latvia, Poland, the Czech Republic and Hungary $(22,26)$.

\begin{tabular}{|c|c|c|c|c|c|c|}
\hline Country & Update period & $\begin{array}{c}\text { Annual eligible } \\
\text { population }\end{array}$ & $\begin{array}{l}\text { Number of } \\
\text { invitations }\end{array}$ & $\begin{array}{c}\text { Number of women } \\
\text { screened }\end{array}$ & $\begin{array}{l}\text { Participation } \\
\text { rate }(\%)\end{array}$ & $\begin{array}{c}\text { Coverage by } \\
\text { test }(\%)\end{array}$ \\
\hline \multirow[t]{2}{*}{ Austria } & 2010 & 200,000 & 200,000 & 27,000 & 13.5 & 13.5 \\
\hline & 2014 & $1,500,000$ & $1,500,000$ & 600,000 & 40.0 & 40.0 \\
\hline Bulgaria & 2013-2014 & $1,057,000$ & 123,647 & 10,392 & 8.4 & 1.0 \\
\hline \multirow[t]{2}{*}{ Czech Republic } & 2013 & 878,576 & $521,187 \mathrm{a}$ & 538,997 & 13.4 & 61.3 \\
\hline & 2010 & 203,336 & 196,578 & 38,148 & 19.4 & 18.8 \\
\hline \multirow[t]{2}{*}{ Latvia } & 2014 & 159,223 & 142,168 & 51,060 & 35.9 & 32.1 \\
\hline & 2010 & $2,522,421$ & $2,419,459$ & 945,283 & 39.1 & 37.5 \\
\hline Poland & 2014 & $2,668,119$ & $2,749,919$ & $1,207,214$ & 43.9 & 45.2 \\
\hline Hungary & 2007 & 751,627 & 393,343 & 205,417 & 52.5 & 27.3 \\
\hline
\end{tabular}

properly analysed to date. There is an urgent public health need to explore the barriers to the OMSP (24). It is important to have a validated instrument to answer this question. The current study examined the factors associated with women's screening behaviour, beliefs, and barriers based on interviews of the target population via questionnaire to assess and report on the psychometric and demographic properties of the barriers leading to low adherence rates in the Hungarian OMSP. Our goal was to acquire information on the appropriate level of intervention necessary to increase screening participation.

Neighbouring Central Eastern European countries such as Poland, the Czech Republic, Bulgaria, Austria and Latvia have similar economies and living standards, and also present low breast screening coverage rates comparable to those in Hungary $(25,26)$ (Table I).
Increased knowledge regarding the barriers to mammography screening may provide information to extend our knowledge of breast cancer screening and effective treatment in Hungary and above mentioned Central-Eastern European countries.

\section{Materials and Methods}

This study was performed in accordance with the Research Ethics Committee of the National Institute of Oncology which conforms to the provisions of the Declaration of Helsinki. The study was performed without additional financial support at the National Institute of Oncology in Budapest between 2015 and 2016. The study received non-financial administrative support from the Hungarian AVON Cosmetics Company and the Mellrákinfó advocacy group.

A cross-sectional survey was designed to examine women's screening behaviour, beliefs, and barriers to OMSP. The Hungarian 
Table II. Questionnaire containing 15 structured questions given to women aged 45-65 years regarding their participation in national organized mammography screening programs in Hungary.

Q1: Age: Q2: Educational level:

Q3: Residence:

Q4: County:

Q5: Marital status:

Q6: Do you undergo mammography examinations?

Q7: If yes, how regularly?

Q8: If yes, how frequently?

Q9: Have you received Invitation Letter for Screening?

Q10: When did you receive Invitation Letter for Screening?

Q11: Do you undergo regular breast screening?

Q12: Where was your last breast exam?

Q13: How far is the designated screening centre from your residence? Q14: Why did you not undergo an organized mammography screening?

\begin{tabular}{c} 
Primary \\
Village \\
Regried \\
\multicolumn{2}{c}{ Yes } \\
Regularly \\
Annually \\
Yes \\
No \\
Norried \\
Organized mammography \\
screening at designated \\
screening centre \\
Close
\end{tabular}

Secondary

Provincial town

Tertiary

Capital

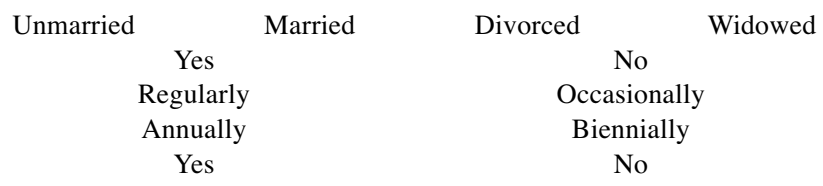

\section{Regularly Occasionally} Opportunistic mammography screening outside of designated screening centre (medical office, private clinic, etc.)

$$
\text { Far Very far }
$$

Because of fear of breast cancer.

Because of fear of mastectomy.

Because the designated screening centre is too far.

Because of my job.

Because I do not have enough information on mammography screening. Because mammography examinations are harmful.

Because I undergo opportunistic mammography screening.

Because mammography examinations are painful.

Because examination of an intimate body part is embarrassing

Because of the expenses to get there.

Other

Q15: What should be changed in order for you to attend the screening program?

breast screening target population of women 45-65 years of age were interviewed anonymously using web-based and printed questionnaires containing 15 structured questions. The questionnaire was designed to assess and report on the psychometric and demographic properties of barriers leading to low participation rates (Table II). The 15-item questionnaire was composed of four sections. The first five questions focused on education level, marital status, residence (capital, provincial town, or village) and county of residence. Three questions focused on mammography receptive behaviour, five questions directly addressed OMSP (receiving invitation letter, participation frequency in mammography screening, distance from screening centre), and two questions focused on barriers that prevented women from attending the screening program.

The sample population was reached via e-mail and Facebook campaign through web-based questionnaires by the Hungarian AVON Cosmetics Company. The questionnaire link was secured by Hypertext Transfer Protocol Secure system. The survey's web-based link was sent to the e-mail contact list and Facebook followers of the Hungarian AVON Cosmetics Company. Printed forms were sent by mail and distributed at local social functions by the Mellrákinfó advocacy group and Hungarian AVON Cosmetics Company. Hungarian AVON used its own contacts to reach the target population.

To ensure that the study sample was representative of the screening population, only surveys from women 45-65 years of age were accepted. Answering the survey questions was voluntary and anonymous. The data protection law was followed and respected. Questionnaires with unreadable or unclear answers were excluded from the analysis.

All answers were statistically analysed in the context of marital status, educational level, and type of residence using chi-square test; $p$-values of less then 0.05 were considered to be significant. Statistical analysis was performed using PAST 1.86 and Statistica 12.0 (StatSoft, Tulsa, OK, USA) (27).

\section{Results}

A total of 58,839 questionnaire links were sent via e-mail, 21,501 links were sent by Facebook campaign, 500 printed questionnaires were mailed, and 293 questionnaires were completed at social events. A total of 12,345 links were opened via e-mail and 5,739 links were opened via Facebook. Overall, 1,774 women 45-65 years of age completed the survey by e-mail, 1,262 on Facebook, 76 forms by mail and 201 at social events. The online response rate was $18.32 \%$ and $15.2 \%$ for mailed forms. A total of 3,313 women between 45 and 65 years of age completed the questionnaire.

The demographic characteristics of the respondents are summarized in Table III. The majority of responders were married, had completed secondary school or lived in provincial towns. 
Descriptive statistical analysis of the answers for structured questions (Q6-Q14) of the questionnaire is shown in Table IV. The questions that focused on barriers to participating were also systematically analysed. A total of 1,042 women responded to the questions regarding their reasons for not undergoing breast screening. Briefly, the main barriers to participation in the OMSP were work absenteeism (18.9\%), fear of painful examination (18.39\%) and false beliefs regarding mammography screening (14.94\%). Of survey respondents, $13.92 \%$ of those who did not attend the OMSP underwent opportunistic screenings; $11.11 \%$ answered that their designated screening centre (DSC) was too far from their home. Only $5.49 \%$ of those who did not participate in screening reported not having enough information on mammography screening and $4.85 \%$ answered that it was too expensive to get to the screening centre. Fear of breast cancer diagnosis prevented $3.58 \%$ of non-participants from attending the OMSP, and $2.04 \%$ did not participate for fear of mastectomy.

Based on patient marital status and place of residence, the responses were analysed to compare a number of criteria. (Table V) There was a significant association $(p=0.029)$ between the responders' marital status and OMSP attendance, with married women attending breast screenings more frequently than single women. There was also a significant difference $(p=0.038)$ between the place of residence and the frequency of mammography examination: women from the capital or from provincial towns more frequently underwent and were more compliant with screening than women who lived in villages. There was a significant association between the responders' residence and the distance from the DSC $(p<0.0001)$ : women living in the capital or provincial towns had better access to their DSC than those living in villages.

There was a significant association between the place of residence and the travel expenses incurred to reach the DSC $(p=0.009)$ (Table VI). Compared to those living in the capital, women in rural populations reported financial difficulties in traveling to their DSC. Female residents of the capital were more likely to choose opportunistic screening compared to those living in rural areas $(p=0.005)$. Barriers such as lack of information on mammography screening $(p=0.001)$ and fear of breast loss $(p=0.003)$ were also significantly associated with lower education level. Educated women were less likely to fear breast cancer and more likely to have sufficient information regarding mammography screening compared to interviewed women with lower levels of education. In the current study, married marital status appeared to be a protective factor against barriers such as feeling embarrassed about the examination $(p=0.0002)$ and expenses incurred to reach the DSC $(p<0.0001)$.
Table III. Responders' demographic characteristics (by response to questions 2, 3, and 5 of the questionnaire, Table II) $(n=3,313)$.

\begin{tabular}{lcc}
\hline Characteristic & No. of responders & $\%$ \\
\hline Marital status & & \\
Unmarried & 153 & $4.62 \%$ \\
Married & 1945 & $58.71 \%$ \\
Divorced & 833 & $25.14 \%$ \\
Widowed & 336 & $10.14 \%$ \\
No answer & 46 & $1.39 \%$ \\
Educational level & & \\
Primary school & 173 & $5.22 \%$ \\
Secondary school & 2106 & $63.57 \%$ \\
Tertiary school & 1005 & $30.34 \%$ \\
No answer & 29 & $0.88 \%$ \\
Place of residence & & \\
Capital & 693 & $20.92 \%$ \\
Provincial town & 1979 & $59.73 \%$ \\
Village & 612 & $18.47 \%$ \\
No answer & 29 & $0.88 \%$ \\
\hline
\end{tabular}

\section{Discussion}

To improve breast cancer screening attendance among Hungarian women, it is imperative to have a valid instrument for exploring and understanding the factors associated with their screening behaviour. Our questionnaire has the appropriate psychometric properties to provide insights into tailor-made strategies designed to address the needs of the screening target population.

Our findings highlight that the main reasons for not attending the OMSP were work absenteeism, fear of pain associated with the examination, and false beliefs regarding mammography screenings. To reduce barriers such as work absenteeism, a paid day off might increase women's willingness to participate in the OMSP. It would be important for employers also to participate in helping their employees utilize preventative measures.

The results of our questionnaire study show that women with lower levels of education were less likely to have adequate information on breast screening, and were more likely to fear mastectomy compared to women with higher levels of education. There is a need for a multi-pronged strategy to inform and educate women about breast awareness and bring about a behavioural change. It may be beneficial to provide more information about breast cancer, breast cancer treatment, and the importance of mammography screening through health awareness education in primary school or through alternative information channels such as magazines, TV advertisements, online sites and brochures. Other authors with similar findings came to the same conclusion (28). 
Table IV. Descriptive statistical analysis of the responses to structured questions (Q6-Q14) of the questionnaire (Table II).

\begin{tabular}{|c|c|c|}
\hline & $\mathrm{n}$ & $\%$ \\
\hline \multicolumn{3}{|l|}{ Q6: Do you undergo mammography examinations? } \\
\hline \multicolumn{3}{|l|}{ Q7: If yes, how regularly? } \\
\hline \multicolumn{3}{|l|}{ Q8: If yes, how frequently? } \\
\hline Yes, annually & 952 & $28.74 \%$ \\
\hline Yes, biennially & 1485 & $44.82 \%$ \\
\hline Yes, occasionally & 540 & $16.30 \%$ \\
\hline No & 290 & $8.75 \%$ \\
\hline No answer & 46 & $1.39 \%$ \\
\hline \multicolumn{3}{|l|}{ Q9: Have you received an Invitation Letter for Screening? } \\
\hline Yes & 2194 & $66.22 \%$ \\
\hline No & 1073 & $32.39 \%$ \\
\hline No answer & 46 & $1.39 \%$ \\
\hline \multicolumn{3}{|l|}{ Q11: Do you undergo regular breast screening? } \\
\hline Regularly & 2359 & $71.20 \%$ \\
\hline Occasionally & 320 & $9.66 \%$ \\
\hline No & 560 & $16.90 \%$ \\
\hline No answer & 74 & $2.23 \%$ \\
\hline \multicolumn{3}{|l|}{ Q12: Where was your last breast exam? } \\
\hline Organized mammography screening in a designated screening centre & 1590 & $47.99 \%$ \\
\hline $\begin{array}{l}\text { Opportunistic mammography screening not in a designated screening centre } \\
\text { (medical office, private clinic, etc.) }\end{array}$ & 1482 & $44.73 \%$ \\
\hline No answer & 241 & $7.27 \%$ \\
\hline \multicolumn{3}{|l|}{ Q13: How far is the designated screening centre from your residence? } \\
\hline Close & 2221 & $67.04 \%$ \\
\hline Far & 884 & $26.68 \%$ \\
\hline Very far & 58 & $1.75 \%$ \\
\hline No answer & 150 & $4.53 \%$ \\
\hline \multicolumn{3}{|l|}{ Q14: Why did you not undergo organized mammography screening? } \\
\hline Because of fear of breast cancer & 28 & $3.58 \%$ \\
\hline Because of fear of mastectomy & 16 & $2.04 \%$ \\
\hline Because the designated screening centre is too far & 87 & $11.11 \%$ \\
\hline Because of my job & 148 & $18.90 \%$ \\
\hline Because I have do not have enough information on mammography screening & 43 & $5.49 \%$ \\
\hline Because mammography examinations are harmful & 117 & $14.94 \%$ \\
\hline Because I undergo opportunistic mammography screening & 109 & $13.92 \%$ \\
\hline Because mammography examinations are painful & 144 & $18.39 \%$ \\
\hline Because examination of an intimate body part is embarrassing & 36 & $4.60 \%$ \\
\hline Because of the expenses to get there & 38 & $4.85 \%$ \\
\hline Other & 276 & $35.25 \%$ \\
\hline
\end{tabular}

Fear of pain in the examination was the second most common reason for avoiding mammography examinations. According to a previous study, discomfort was reduced when women were provided with written or verbal information, and when a breast cushion was used (29). Providing verbal or written information, as well as supporting women during the examination, is a simple and easily achievable intervention and can help to reduce pain during screening mammography. Use of alternative breast compression strategies or premedication with acetaminophen has not been reported to significantly reduce breast pain and discomfort (29).

It is important to note that half of responders in the current study chose opportunistic screening and that $13.92 \%$ of non- participants chose a location other than their DSC for their mammography examinations. This finding is consistent with reports that opportunistic screening only covers half of the screened target population in Hungary (21-23). The nonparticipants described other barriers such as long waiting times in clinics, unorganized DSCs, dissatisfaction with facility staff, difficulties in changing scheduled mammogram appointments, and a lack of concern about breast cancer. To increase screening attendance rates, these barriers should also be addressed. The environment and facility staff are important for women's satisfaction and their willingness to attend their next screening. Similar barriers and suggestions have been described in other studies (30-33). A patient 
Table V. Significant associations between patient marital status, residence, and responses to the questionnaire (by response to questions 3, 5-8, and 13, Table II).

\begin{tabular}{|c|c|c|c|c|c|}
\hline \multirow{2}{*}{$\begin{array}{l}\text { Factor } \\
\text { Screening }\end{array}$} & & \multicolumn{2}{|c|}{ Response } & \multirow[b]{2}{*}{ No } & \multirow[t]{2}{*}{$p$-Value* } \\
\hline & & Regularly & Occasionally & & \\
\hline Unmarried & & 97 & 21 & 30 & 0.029 \\
\hline Married & & 1438 & 165 & 320 & \\
\hline Divorced & & 588 & 89 & 148 & \\
\hline Widow & & 228 & 42 & 60 & \\
\hline Mammogram & Annually & Biennially & Occasionally & No & \\
\hline Capital & 221 & 285 & 123 & 60 & 0.038 \\
\hline Provincial town & 565 & 925 & 317 & 160 & \\
\hline Village & 166 & 275 & 100 & 70 & \\
\hline Distance from DSC & & Close & Far & Very far & \\
\hline Capital & & 476 & 184 & 7 & $9.5 \times 10^{-17}$ \\
\hline Provincial town & & 1413 & 450 & 35 & \\
\hline Village & & 332 & 250 & 16 & \\
\hline
\end{tabular}

DSC: Designated screening centre. *Chi-square test.

Table VI. Statistical analysis of significant barriers to undergoing mammography screening associated with socioeconomic status (answer to question 14: Why did you not undergo organized mammography screening?).

\begin{tabular}{|c|c|c|c|c|c|}
\hline \multirow[b]{2}{*}{ Answer to Q14 } & \multirow[b]{2}{*}{ Factor } & \multirow[b]{2}{*}{ Status } & \multicolumn{2}{|c|}{ Response, $\mathrm{n}$} & \multirow[b]{2}{*}{$p$-Value* } \\
\hline & & & Chosen & Not chosen & \\
\hline \multirow[t]{3}{*}{ Because I attend other mammography screening } & \multirow[t]{3}{*}{ Location } & Capital & 39 & 147 & \multirow[t]{3}{*}{0.005} \\
\hline & & Provincial town & 50 & 401 & \\
\hline & & Village & 20 & 126 & \\
\hline \multirow[t]{7}{*}{ Because of the expenses to get there } & \multirow[t]{3}{*}{ Location } & Capital & 3 & 183 & \multirow[t]{3}{*}{0.009} \\
\hline & & Provincial town & 22 & 429 & \\
\hline & & Village & 13 & 133 & \\
\hline & \multirow[t]{4}{*}{ Marital status } & Unmarried & 2 & 44 & \multirow[t]{4}{*}{$2.1 \times 10-5$} \\
\hline & & Married & 10 & 421 & \\
\hline & & Divorced & 12 & 198 & \\
\hline & & Widowed & 13 & 78 & \\
\hline \multirow[t]{3}{*}{ Because of fear of mastectomy } & \multirow[t]{3}{*}{ Education } & Primary & 4 & 43 & \multirow[t]{3}{*}{0.003} \\
\hline & & Secondary & 10 & 487 & \\
\hline & & Tertiary & 2 & 237 & \\
\hline \multirow[t]{3}{*}{ Because I do not have enough information } & \multirow[t]{3}{*}{ Education } & Primary & 8 & 39 & \multirow[t]{3}{*}{0.001} \\
\hline & & Secondary & 26 & 471 & \\
\hline & & Tertiary & 9 & 230 & \\
\hline \multirow{4}{*}{$\begin{array}{l}\text { Because undergoing examination of an } \\
\text { intimate body part is embarrassing }\end{array}$} & \multirow[t]{4}{*}{ Marital status } & Unmarried & 3 & 43 & \multirow[t]{4}{*}{0.0002} \\
\hline & & Married & 12 & 419 & \\
\hline & & Divorced & 8 & 202 & \\
\hline & & Widowed & 12 & 79 & \\
\hline
\end{tabular}

*Chi-square test.

navigator system could utilize prevention nurses to organize an effective screening program by offering education on breast awareness, screening invitation, and management of biennial mammogram appointments (34).

Only two-thirds of responders had received an Invitation Letter for Screening (ILS) in the previous 2 years, which is below the minimum $70 \%$ adherence rate required by the WHO to reduce breast cancer mortality (20). Further investigations are needed to determine the causes for the lack of receipt of ILS.

In our study, the fear of breast cancer and fear of mastectomy among non-participants emphasizes the barriers 
to participating in the OMSP. This finding is similar to a previous study where cancer anxiety and worry were associated with avoidance of breast cancer screening (35).

Married status appeared to be a protective factor against barriers, including embarrassment regarding the examination, financial challenges associated with travelling to the DSC and avoiding breast screening. Single women, mainly widows, were more likely to skip or were less likely to participate in the OMSP compared to married women. There is strong positive association between relationship and participation behaviour in mammography screening, which is also supported by other authors (36). Single women require special attention to inform them about the importance of breast screening, which could be addressed through wellorganized patient navigation programs, as well as breast cancer support groups and self-help organizations.

In subjective response to the question "How far is the designated screening centre from your residence?", onequarter of women answered far, while fewer than $2 \%$ answered very far. Excessive distance to reach the DSC was the fifth most frequent barrier to breast screening. Statistical comparative analyses indicated that living in villages or in single households were associated with lower participation rates because of financial difficulties and problems in travelling long distances to the DSC. Others concluded similarly that women living in rural areas were less likely to participate in OMSPs compared with those living in urban areas (37). According to a previous interview-based survey, time required to travel to and distance from the DSC are important factors for women (38). Well-situated units with advanced promotion about public transportation and parking facilities may encourage greater uptake. Rural women require special attention because of their lower participation rates in mammography examination. Patient navigation, free public transport for the day of screening, specialized roundtrip bus lines, or mobile breast screening units may help to overcome these barriers.

In conclusion, our findings highlight that the main reasons for women to avoid participation in OMSP included work absenteeism, fear of painful examination, lack of adequate information, and false beliefs about mammography screenings.

\section{Conflicts of Interest}

The Authors received non-financial administrative support from the Hungarian Avon Cosmetics Company and Mellrákinfó advocacy group.

\section{Financial Support}

The study was performed without additional financial support at the National Institute of Oncology in Budapest.

\section{Acknowledgements}

The Authors thank the Hungarian Avon Cosmetics Company and Mellrákinfó for providing non-financial administrative support for this study. We express special thanks to Professor Dr. Joseph Molnar from the University of Szeged, Faculty of Medicine for critical review of the article.

\section{References}

1 Duffy SW, Tabár L, Chen H-H, Holmqvist M, Yen M-F, Abdsalah S, Epstein B, Frodis E, Ljungberg E, HedborgMelander C, Sundbom A, Tholin M, Wiege M, Åkerlund A, Wu H-M, Tung T-S, Chiu Y-H, Chiu C-P, Huang C-C, Smith RA, Rosén M, Stenbeck M and Holmberg L: The impact of organized mammography service screening on breast carcinoma mortality in seven Swedish counties. Cancer 95: 458-469, 2002.

2 Tabar L, Vitak B, Chen HH, Yen MF, Duffy SW and Smith RA: Beyond randomized controlled trials: organized mammographic screening substantially reduces breast carcinoma mortality. Cancer 91: 1724-1731, 2001.

3 Hellquist BN, Duffy SW, Abdsaleh S, Björneld L, Bordás P, Tabár L, Viták B, Zackrisson S, Nyström L and Jonsson H: Effectiveness of population-based service screening with mammography for women ages 40 to 49 years. Cancer 117: 714-722, 2011.

4 Boncz I, Sebestyen A, Pinter I, Battyany I and Ember I: The effect of an organized, nationwide breast cancer screening programme on non-organized mammography activities. J Med Screen 15: 14-17, 2008.

5 Andersson I, Aspegren K, Janzon L, Landberg T, Lindholm K, Linell F, Ljungberg $\mathrm{O}$, Ranstam $\mathrm{J}$ and Sigfusson $\mathrm{B}$ : Mammographic screening and mortality from breast cancer: the Malmo mammographic screening trial. BMJ 297: 943-948, 1988.

6 Tabar L, Fagerberg CJ, Gad A, Baldetorp L, Holmberg LH, Grontoft $\mathrm{O}$, Ljungquist $\mathrm{U}$, Lundstrom B, Manson JC and Eklund: Reduction in mortality from breast cancer after mass screening with mammography. Randomised trial from the Breast Cancer Screening Working Group of the Swedish National Board of Health and Welfare. Lancet 1: 829-832, 1985.

7 Kopans DB and Feig SA: The Canadian National Breast Screening Study: a critical review. Am J Roentgenol 161: 755$760,1993$.

8 Nystrom L, Rutqvist LE, Wall S, Lindgren A, Lindqvist M, Ryden S andersson I, Bjurstam N, Fagerberg G, Frisell J, Tabár L and Larsson L-G: Breast cancer screening with mammography: overview of Swedish randomised trials. Lancet 341: 973-978, 1993.

9 Nystrom L andersson I, Bjurstam N, Frisell J, Nordenskjold B and Rutqvist LE: Long-term effects of mammography screening: updated overview of the Swedish randomised trials. Lancet 359: 909-919, 2002.

10 Esserman L, Shieh Y and Thompson I: Rethinking screening for breast cancer and prostate cancer. JAMA 302: 1685-1692, 2009.

11 Kalager M, Zelen M, Langmark F and Adami HO: Effect of screening mammography on breast-cancer mortality in Norway. N Engl J Med 363: 1203-1210, 2010.

12 Autier P, Boniol M, LaVecchia C, Vatten L, Gavin A, Héry C and Heanue M: Disparities in breast cancer mortality trends between 30 European countries: retrospective trend analysis of WHO mortality database. BMJ 341: c4480, 2010. 
13 Ujhelyi M, Pukancsik D, Kelemen P, Kovacs E, Kenessey I, Udvarhelyi N, Bak M, Kovacs $\mathrm{T}$ and Matrai Z: Does breast screening offer a survival benefit? A retrospective comparative study of oncological outcomes of screen-detected and symptomatic early stage breast cancer cases. Eur J Surg Oncol 42: 1814-1820, 2016.

14 Marmot MG: Sorting through the arguments on breast screening. JAMA 309: 2553-2554, 2013.

15 Weigel S, Heindel W, Heidrich J, Heidinger O and Hense HW: Reduction of Advanced breast cancer stages at subsequent participation in mammography screening. RoFo: Fortschritte auf dem Gebiete der Rontgenstrahlen und der Nuklearmedizin 188: 33-37, 2016.

16 Autier P, Hery C, Haukka J, Boniol M and Byrnes G: Advanced breast cancer and breast cancer mortality in randomized controlled trials on mammography screening. J Clin Oncol 27: 5919-5923, 2009.

17 Tabar L, Gad A, Holmberg L and Ljungquist U: Significant reduction in advanced breast cancer. Results of the first seven years of mammography screening in Kopparberg, Sweden. Diagn Imag Clin Med 54: 158-164, 1985.

18 Kasler M, Otto S and Kenessey I: The current situation of cancer morbidity and mortality in the light of the National Cancer Registry. Orv Heti 158: 84-89, 2017.

19 Hungarian National Cancer Registry. http://ghdx.healthdata.org/ organizations/national-cancer-registry-hungary-10

20 Perry N, Broeders M, de Wolf C, Tornberg S, Holland R and von Karsa L: European guidelines for quality assurance in breast cancer screening and diagnosis. Fourth edition--summary document. Ann Oncol 19: 614-622, 2008.

21 Boncz I, Dobrossy L, Pentek Z, Kovacs A, Budai A, Imre L, Vajda R and Sebestyen A: [Attendance of the fourth (2008-2009) screening round of the Hungarian organized, nationwide breast cancer screening program]. Orv Hetil 154: 1975-1983, 2013.

22 Boncz I, Dobrossy L, Pentek Z, Kovacs A, Budai A, Vajda R and Sebestyen A: Participation rates in the third round (2006-2007) of the breast cancer screening program in Hungary. Magy Onkol 57: 140-146, 2013.

23 Boncz I, Sebestyen A, Dobrossy L, Pentek Z, Kovacs A, Budai A, Kovi R and Ember I: Attendance in the second phase (20042005) of the Hungarian organized breast cancer screening program. Orv Hetil 149: 1491-1498, 2008.

24 Schueler KM, Chu PW and Smith-Bindman R: Factors associated with mammography utilization: a systematic quantitative review of the literature. J Women's Health 17: 1477-1498, 2008.

25 Giordano L, von Karsa L, Tomatis M, Majek O, de Wolf C, Lancucki L, Hofvind S, Nystrom L, Segnan N, Ponti A, Eunice Working G, Van Hal G, Martens P, Majek O, Danes J, von Euler-Chelpin M, Aasmaa A, Anttila A, Becker N, Pentek Z, Budai A, Madai S, Fitzpatrick P, Mooney T, Zappa M, Ventura L, Scharpantgen A, Hofvind S, Seroczynski P, Morais A, Rodrigues V, Bento MJ, Gomes de Carvalho J, Natal C, Prieto M, Sanchez-Contador Escudero C, Zubizarreta Alberti R, Fernandez Llanes SB, Ascunce N, Ederra Sanza M, Sarriugarte Irigoien G, Salas Trejo D, Ibanez Cabanell J, Wiege M, Ohlsson G, Tornberg S, Korzeniewska M, de Wolf C, Fracheboud J, Patnick JJ, Lancucki L, Ducarroz $S$ and Suonio E: Mammographic screening programmes in Europe: organization, coverage and participation. J Med Screen 19(Suppl 1): 72-82, 2012.
26 Deandrea S, Molina-Barcelo A, Uluturk A, Moreno J, Neamtiu L, Peiro-Perez R, Saz-Parkinson Z, Lopez-Alcalde J, Lerda D and Salas D: Presence, characteristics and equity of access to breast cancer screening programmes in 27 European countries in 2010 and 2014. Results from an international survey. Prev Med 91: 250-263, 2016.

27 Hammer O, Harper DAT and Ryan PD: PAST: Paleontological Statistics software package for education and data analysis. Paleontol Electron 4(1): 1-9, 2001.

28 Ackerson $\mathrm{K}$ and Preston SD: A decision theory perspective on why women do or do not decide to have cancer screening: systematic review. J Adv Nurs 65: 1130-1140, 2009.

29 Miller D, Livingstone V and Herbison P: Interventions for relieving the pain and discomfort of screening mammography. Cochrane Database Systematic Rev 2008: CD002942, 2008.

30 Sarwar MZ, Hassan Shah SF, Yousaf MR, Ahmad QA and Khan SA: Knowledge, attitude and practices amongst the Pakistani females towards breast cancer screening programme. J Pakistan Med Assoc 65: 1075-1078, 2015.

31 Khokhar A: Study on knowledge, experiences and barriers to mammography among working women from Delhi. Ind J Cancer 52: 531-535, 2015.

32 Peipins LA, Shapiro JA, Bobo JK and Berkowitz Z: Impact of women's experiences during mammography on adherence to rescreening (United States). Cancer Causes Control 17: 439-447, 2006.

33 Bairati I, Turcotte S, Doray G, Belleau F and Gregoire L: Development and validation of an instrument assessing women's satisfaction with screening mammography in an organized breast cancer screening program. BMC Health Serv Res 14: 9, 2014.

34 Percac-Lima S, Ashburner JM, Zai AH, Chang Y, Oo SA, Guimaraes E and Atlas SJ: Patient navigation for comprehensive cancer screening in high-risk patients using a population-based health information technology system: a randomized clinical trial. JAMA Intern Med 176: 930-937, 2016.

35 Pfeffer N: Screening for breast cancer: candidacy and compliance. Social Sci Med 58: 151-160, 2004.

36 Achat $\mathrm{H}$, Close $\mathrm{G}$ and Taylor R: Who has regular mammograms? Effects of knowledge, beliefs, socioeconomic status and health-related factors. Prev Med 41: 312-320, 2005.

37 Ouedraogo S, Dabakuyo-Yonli TS, Roussot A, Pornet C, Sarlin N, Lunaud P, Desmidt P, Quantin C, Chauvin F, Dancourt V and Arveux P: European transnational ecological deprivation index and participation in population-based breast cancer screening programmes in France. Prev Med 63: 103-108, 2014.

38 Linsell L, Forbes LJ, Patnick J, Wardle J, Austoker J and Ramirez AJ: Women's preferences for the delivery of the National Health Service Breast Screening Programme: a crosssectional survey. J Med Screen 17: 176-180, 2010. 